\title{
Analyzing the Prophet Mohammad's Symbolic Horse in His Spiritual Ascension
}

\author{
Tayebe Jafary ${ }^{1} \&$ Morteza Hashemi ${ }^{1}$ \\ ${ }^{1}$ Literature Department, University of Isfahan, Isfahan, Iran \\ Correspondence: Tayebe Jafary, Literature Department, University of Isfahan, Isfahan, Iran. Tel: \\ 98-913-218-2149. E-mail: liutjafary@yahoo.com
}

\author{
Received: August 11, 2012 Accepted: October 3, 2012 Online Published: December 28, 2012 \\ doi:10.5539/ach.v5n1p74 \\ URL: http://dx.doi.org/10.5539/ach.v5n1p74
}

\begin{abstract}
Beginning from the ancient times human has always valued the historical individuals and events and by exaggerating their features and circumstances have created mythical and audacious characters and phenomena. In the history of Islam the same is true regarding the Prophet Mohammad in its unique manner, that accounts for his spiritual ascension and a mythic horse named Boraq. The wonder of the ascension somehow highlighted the other events of in the Prophet Mohammad's life and since "horse" has been an essential element in human life and no heroism was not accomplished without it, in a short span of time Boraq was converted into a super-natural and mythical being. Based on the available sources the Boraq has to unique features that make it be different from other mythical horses: it was brought from the heavens by an angle and the horse shaped body had a human(female) head with two big wings, a combination of human, animal and bird. This extra ordinary creature the existence of which beyond imagination in reality is a mythical being the unique features of which is acceptable only by correlating them to the eminent symbols and archetypes acknowledge by C.G.Jung. In this perspective eminent horse with a human head represent and image of the prophet unconscious Anima where the four legs justify the four stage of Anima and the big wings are the conception of the transcendence, holiness and motion toward the heavenly realm.
\end{abstract}

Keywords: spiritual ascension, Boraq, archetype, wing, anima

\section{Introduction}

The spiritual ascensions of the prophet Mohammad is a holy event, even expressed in the Quran. His holiness was taken from Holy Masque to The Noble Sanctuary for a special observation of same Godly signs (Sureh Al-Isra). According to the available narrations, the prophet of the Islam in the night of ascendants rode a horse named Boraq, an Arabic name most probably naming illumination. According to Islamic believe, Gabriel brought this animal from the heavens, a horse-shaped-winged mount slightly smaller than a mule. In some non-Islamic and archetypal narration this mythical animal has been presented as the prophet Abraham's mount and is said that he went to Mecca to his wife, Hajer, every morning and to his other wife Sara in evening riding on this animal (Rosenberg, 1996). Among the other events in the Prophet Mohammad's life, the wonder caused by the ascension attracted more attention to a point that by exaggeration it became myth. It is a well-known fact that in all myths and fables the hero of the epic is always accompanied with a wonderful horse, here Boraq is categorized as one of these mythical horses during time. The extra ordinary features of Boraq in a sense have their roots in the monumental outstanding works of other civilization and this fact indicates that these features should be evaluated through the existing bond between myths and legends in addition to the symbolic conceptions and archetypes. By doing so the ascension process through Boraq which is a symbolic event would be determined.

Investigating the related literature indicate lack of the motives of such events and the similar experiences and simples thereof. The only philosophical approach to the issue could be found Ibn-Sina's devoted work to the prophet's ascension which was depicted from Ebrahim Abarghui's works. In this article this issue will be discussed in its proper section. This revealed vacancy regarding the issue at hand is the motive that derives the authors of this article to present a new perspective and leave the rest of the matters for another occasion.

The approach in this article follows the reference to some comments on the literature devoted to transcendent in prose and poetic and famous miniature paintings sequence. Then some similar symbolic creature in the mythic 
aspects of other nations are investigated in order to determined rational behind the attribution of such features to the horse from the heavens that look the prophet to his descendent. This phenomenon is rooted in the global ancient thought and is manifested differently in given cultures and traditions. After presenting these samples in the main section would assess Jung's views on mythical visage and explain the archetype of the symbolic aspect of the issue.

\section{The Visage of Boraq in Works}

In a general sense the devoted works to the ascension issue are categorized in two:

The text, that is again categorized in two: first the Quranic comments through some verses dealing with gnosis aspect of the ascension event. It is interesting to know that the first attributions regarding Boraq are found in Quranic comments, and second, the literature devoted to the ascension event in prose and poetic.

The visual arts: in this field the miniaturists' subject is the ascension event of the prophet and they have left some monumental works in this respect.

\subsection{The Visage of Boraq in Quranic Comments}

All Islamic commentators are of the same opinion comments on the prophet's ascension by a horse from the heavens named "Boraq" but their characterization of this horse is different. In this study the emphasis is on the visage of Boraq that has a human (female) face and two big wings that represent a creature with a combination of human, animal and bird features. In many commentators it is referred to:

"Gabriel brought the Boraq; an animal bigger than a donkey, smaller than a mule, with a human visage, cow-tailed, mane like a horse, camel-legged from the heavens" (Moosavi Hamedani, 1995).

"Gabriel brought the Boraq, an animal bigger than a donkey, smaller than a mule, with a human visage, cow-tailed, horse-naked, camel-legged endowed with heavenly ornament, the two wings on the thighs and told me, to mount it"

His holiness the prophet said "the Boraq sent to me by God is a heavenly animal that is not very tall or short, its face is like human face and the eyes shine like the stars" (Vaezzadeh Khorasani, 1998).

\subsection{The Visage of Boraq in Ascension-epistle}

The ascension phenomenon, due to its importance in hagiography of prophet Mohammad and the interpretations of the Quran verses in this regard made its way in the Farsi literature and contributed to some outstanding literary works like: "The description of ascension" by Hamidodin Nagoori, "The epistle of ascension" by Shamsodin Mohammad Aflaki, the same title by Mobarak Bokharai, "Unity of the ascending arcs" by Shah Nematolahe Valie Kermani, "The epistle of ascension" by Ebrahim Abarghoi. Among all this, Ibn-Sina has the following with respect to justification of the human faced attribution "... and that he said 'its visage resembled human, that is, it was apt to have human training"' (Ibn-Sina, 1986). Ebrahim Abarghuhi has depicted the same view in his work. As mentioned before, Ibn-Sina and his follower Abarghuhi are the only ones who have evaluated the ascension event under the Islamic gnosis perspective.

Sanai Ghaznavi was the first poet who extracted the concept of the issue from the available prose and converted into poem. The great poet "Nezami", influenced by the previous works touched the issue of ascension in the acknowledgment section of all his five long poems. In his "Treasury of secrets" he resembles the Al-Boraq's speed to a hawk as white as a pigeon (Nezami, 2001). According to Nezami (2005), in his "Seven corpus" when the prophet mounted Al-Boraq peacock feathers emerged from the animals legs that made it fly. Khaghani Shervani, 1954 in his "Tohfatolaraghein" points to the human faced nature of Al-Boraq.

\subsection{The Visage of Boraq in Miniatures}

During time on constant bases the outstanding and monumental events, famous characteristics and anything that was essential for cultural and religious values of a tribes, nation, and race has left their reflective makes and traces in the visual arts.

Prophet Mohammad's ascension, as an essential religious phenomenon in Moslem world has been illustrated in different forms and shapes. These paintings, with the prophet mounted on semi-mythical Boraq illuminates the poetry books, prose and in specific the five volumes of Nezami's poetry or as a separate framed painting. According to the Encyclopedia of Islam the oldest figures of Al-Boraq have been drawn in the fourth century A.C with a feminine crowned head (E. Campo). The following pictures represent some of the outstanding samples: 


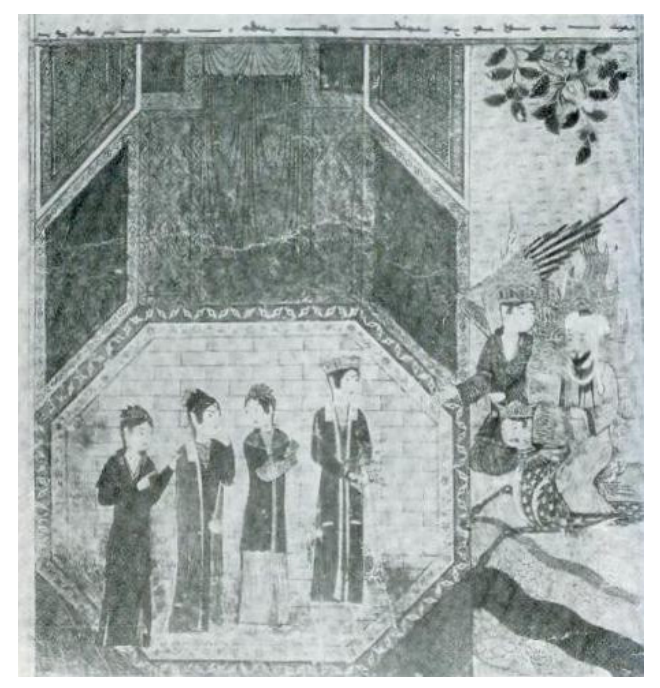

Figure 1. Ascension, Herat's School, the National Library of Paris

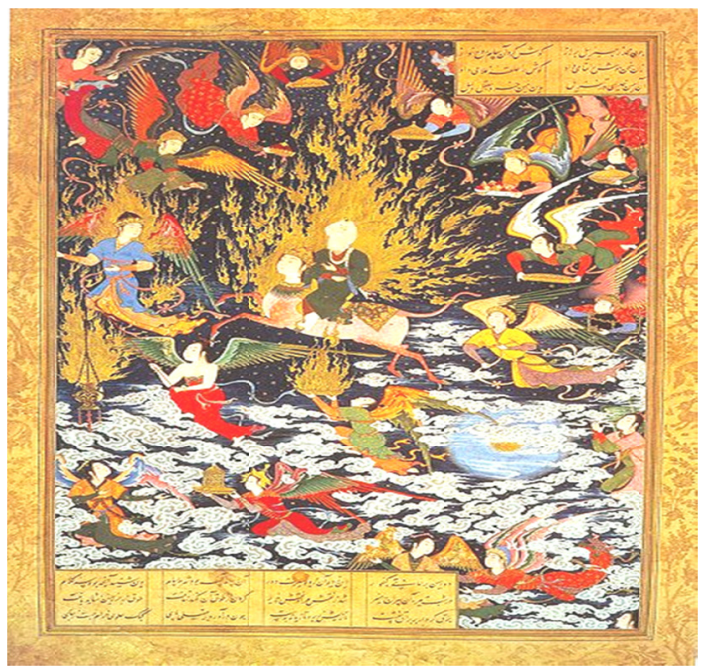

Figure 2. Nezami's Khamse, Tabriz's School, painted by Soltan Mohammad, British Museum

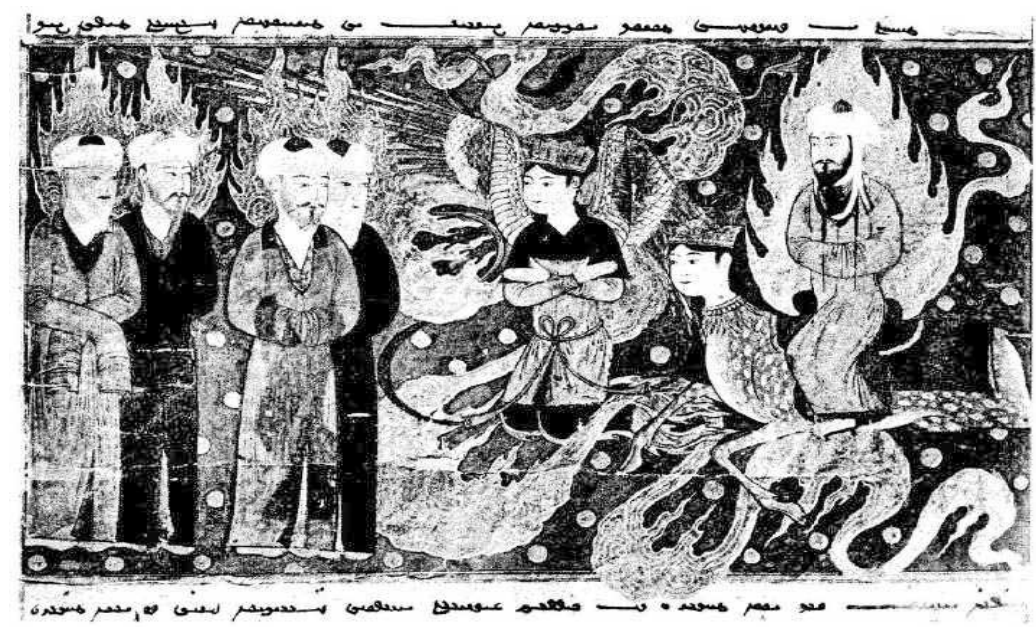

Figure 3. Painted in 1436 in Herat, Afghanistan, the National Library of Paris 


\section{Human-animal in Mythology}

Based on what has been discussed the essence of Boraq is in its human-animal mixed natured appearance with no mention of its gender while in some paintings feminine visage is evident. A painting of human-animal or the opposite is common in mythical literature of almost all cultures in vast volumes. The samples are: the Sphinx in Greek mythology; Abolhole a giant, a celestial being from the Hell with a feminine head and curly hair and a body of winged lion; Triton, a celestial multi faced God-man with a face of a man with two big fish tails below the belt; Chiron one of the Centaurs a half man-half horse; Minotaur, a big and ugly giant with human body and bull hand (Schmidt, 2008). In Egypt a relief depicts eagle headed winged beast in the "Ashur Bani Pal" castle dated $9^{\text {th }}$ century A.C (Warner, 2010).

Human-animal image in the monumental works in ancient Iran are numerous. On a cylindrical seal two men scorpions are standing under the Ahura's image. In another ancient relief two crowned Sphinxes with lion body and male head are seen standing under the Ahura's symbol the winged half circle (Warner, 2010). The Boraq that is the special mount of the prophet Mohammad is one of the monumental symbols of Islamic culture with an ancient conception that embodies vast spectrum of definitions and makes the archetype commentators like C.G.Jung (1978) to evaluate and collaborate on that would be discussed later.

\section{Analyzing the Archetypal and Symbolic Function of Boraq}

\subsection{The Symbolic Function of Boraq as a Horse}

In the analysis of the archetypal and symbolic function of Boraq, first the "horse" and the "rider" should be analyzed. According to Jean Chevalier, the heavenly horse depicts the tamed intuitive knowledge, it is obedient that reflects ethics, the noblest feature of mankind (Chevalier, 2005). Based on this definition the "rider" as is in control of the mount that prevail the evil. The "rider" ascends to the heavens towards the Gods, the heroes and the novel exactly like the renowned painting of the prophet riding on the Boraq guided by Gabriel towards the celestial Throne passing among the angles. Under these circumstances the rider reveals a conceptual meaning, something like materialization of the holy words and seeking actualization... the painting, the symbol of self-inhibition and superiority over natural forces (Chevalier, 2005). In parallel to this symbolic nature of the issue, Qaje Mohammad Parsa recognizes the mount as animal-self that has the rational souls on its back something similar to the believe that animal-selves ride the human body (Parsa, 1987). According to Chevalier if the upper half of the human-shaped animal is the human head it has a positive meaning since the upper part of the human body has supreme properties compared to the lower parts and is closer to the heavens.

\subsection{The Symbolic Function of Boraq as a Winged-horse}

The other outstanding feature of Boraq is it's having wings, a symbol of ascension. As Socrates would say, wings and feather are the closest parts of the body to the God because they manifest tendency towards the sky (Zomorodi, 2007). According to the dictionary of symbols by Chevalier, before being anything else, wings are the symbol of flight and lightness. It seems almost detected from the body and manifests the nature of becoming released from whatever, soul, material, spirits etc. The wing is the passage to corporal body. In far eastern traditions, Shamanism, east or west, Moslem, Christian Hebrew or other all are of consent on this issue; since, the flight of soul and flight of, Shaman have the virtual sense of being freed from the core of the earth, this conception is similar to the philosophy of esotericisms in the alchemy where an angel devouring of the lion is depicted. In the mythology of all cultures the wing is not given but is gained with inner training and purification of the ego in a very long-term full of risks and challenges (Chevalier, 2005).

\subsection{The Function of Boraq as Anima}

In the evaluation proses of Boraq in addition to the symbolic concepts of the horse and archetypal approach is of essence too. According to the great anthropologist Jung, Carl Gustav, any individual has an emotional mute with a gender other than his/her own, said otherwise in every man these is a women and vice-versa; whom he calls Anima and Animus each in four forms; hence the essence of number four in emotional functional faculty(Jung, 1964).

Jung counts four fundamental stages for Anima: "The first stage is best symbolized by the figure of Eve, which represents purely instinctual and biological relations. The second can be seen in Faust's Helen: She personifies a romantic and aesthetic level that is, however, still characterized by sexual elements. The third is represented, for instance, by the Virgin Marry, figure who raises love Eros to the heights of spiritual devotion. The fourth type is symbolized by Sapientia, wisdom transcending even the most holy and the most pure. Of this another symbol is the Shulamite in the Song of Solomon. (In the psychic development of modern man this stage is rarely reached. I 
he Mona Lisa comes nearest to such a wisdom Anima)." (Jung, 1964).Based on the statements above, Boraq with a head of female shows the complete connection between the contraries of existence and its rider.

In reality Boraq is the unconscious Anima of the prophet that is a symbolic manner contributes to his acceptance in the highest of gnosis ascension. The Anima function is justified by this visage and being a quadruped justifies the archetypal nature of the concept, hence the four stage of Anima symbolized in one body.

\section{Conclusion}

Boraq is a horse brought from the heavens to tack the prophet of Islam on his descent and in this gnosis experience the prophet meets God. According to the available sources that include Qoranic commentaries, literature devoted to the prophet's descent in prose and poetry and the miniatures Boraq has human head, presented in female face in the miniatures. It has two big wings, therefore it is a combination of human, animal and bird that represents a symbolic and mythic creature, the samples of which whit a little difference could be found in other cultures, mythological works. A quadruped creature with these unique Features cannot be considered as an ordinary animal. It should be observed in symbolic and exegetic manner. Based on this view point that is in agreement with that of Jung's, the Prophet descent event should be taken as a gnosis event the intrinsic aspect of which indicates the grate evolution that the Prophet goes through so he, according to Jung's interpretation of God within one's self. According to these symbolic explanations, the Boraq in this mythic process, due to its unique functionality gains archetypal nature. The quadruped nature represents the four stage of Anima that encompasses the inferior and the superior elements. The two wings that give the Boraq a sense of holiness indicate the means of going from multiplicity to unity. The discordance occurrence corresponds to the revelation of Islam and it is not blended with the ancient myth and fable. There is no doubt that in certain areas in the related literature some elements reveal that their roots go back to the archetypal concepts the samples of which are common in many cultures that have ancient history.

\section{References}

Chevalier, J., \& Gheerbrant, A. (2005). Dictionnaire des symbols. Tehran, Jeihoon (In Persian).

Ibn-Sina. (1986). The ascension. Mashhad.

Jung, C. G. (1964). Man and his symbols. USA: Anefor Press.

Moosavi, H., \& Seyed, M. B. (1995). Translate of Almizan. Ghom.

Nezami, G., \& Eliasebne, J. (2001). HaetPeikar. Tehran.

Nezami, G., \& Eliasebne, J. (2005). Makhzanolasrar. Tehran.

Parsa, M. (1987). FosooseParsa. Tehran.

Rosenberg, D. (1996). Myth of Orient. Mashhad (In Persian).

Schmidt, J. (2005). Dictionnaire de la mythologie grecqueet Romaine. Tehran (In Persian).

Vaezzade, K. (1998). TafsireJamea. Mashhad.

Warner, R. (2010). Encyclopedia of mythology. Tehran (In Persian).

Zomorodi, H. (2007). A comparative comment of religions and myths. Tehran. 